\title{
Feasibility of Using Poetry in a Textmasters' Environment to Teach Mathematics to Secondary School Students
}

\author{
Dr. Chinyere H Maduabuchi \\ Department of Arts and Social Science Education, Faculty of Education \\ Ebonyi State University, Abakaliki, Ebonyi State, Nigeria \\ E-mail: ettachimlo@yahoo.com
}

Ukamaka Martha Maduagwu (Corresponding author)

Department of Educational Foundations

Ebonyi State University, Abakaliki, Ebonyi State, Nigeria

E-mail: makasdabby@yahoo.com

Received: November 13, 2014 Accepted: December 12, $2014 \quad$ Published: December 14, 2014

doi:10.5296/ijele.v3i1.6785 URL: http://dx.doi.org/10.5296/ijele.v3i1.6785

\begin{abstract}
Most Nigerian students, do exhibit phobia for mathematics and its related disciplines because of its abstract and wired nature. Poetry being one of the genres of literature has its peculiarity of lyrical entertainment. Textmasters strategy establishes collaborative learning environment of literature circles in content areas. Students in textmasters are placed in groups of four with the roles of Discussion Director, Summarizer, Vocabulary Enrincher and Webmaster. They are often given a schedule of the reading of the upcoming chapter. All the students read the same section of the book, but usually complete a role sheet to guide their perspectives: Reading aloud of any entertaining and informative poems normally spark students' interest in posing and solving mathematics problems through textmasters. For example, while reading aloud, the students are actively involved and constantly comment on how the poems connect to mathematics, especially how they describe and illustrate the concepts, in this instance, simple interest.. This paper, proposes the feasibility of using poetry to teach mathematics in a textmasters' environment. It tries to explore the nature and concepts of textmasters and poetry in mathematics teaching; the connections between mathematics and literature; and practical
\end{abstract}


steps in a textmasters' environment for the teaching of mathematics through poetry. The crux of the matter is for teachers to see poetry as a wonderful aid that could assist in the teaching of the often dreaded mathematics. It is hoped that it will help teachers to investigate and reflect more on the power and potential of an interdisciplinary curriculum.

Keywords: Textmasters' environment, poetry, mathematics, simple interest

\section{Introduction}

\subsection{Background}

Reading practices in the classrooms have necessitated the birth of so many reading strategies that have helped comprehension. One of such reading strategies is the literature circles, which were described by Harvey Daniel in the early 1990s (Daniels 1994).In literature circle's classroom, students are shared into groups, given roles and made to sit in a circle to discuss issues from the fictions under study. During sessions, students assume various "roles" that guide their reading (Peterson and Belizaire, 2006). Students meet on a regular basis to discuss agreed-upon sections of the book, and rotate the roles that they were given amongst the members of the group (Wilfong, 2009). Traditionally, literature circle strategy was applied to fiction, but it has recently been updated and used with a variety of texts including non-fictions. Researchers have examined and concluded that the discourses that take place during literature circles are often purposeful and critically minded (Sandmann and Gruhler, 2007). Literature circles, as cited by Johnson in Wilfong, (2009:165):

Has been found to empower students who thrive in the small group setting, allowing for marginalized voices to be heard, students often feel an increased sense of responsibility towards their group and their own learning through the use of various roles and discussion

Textmasters is a brain child of literature circles that sprang from the need expressed by a group of graduates, who were taught reading in the content areas using literature circles. It is an enhanced version of literature circles that is directed at teaching non-fiction and content areas' reading. According to Wilfong (2009), the proponents of this strategy examined the traditional literature circle roles and new ones created by practitioners and selected four roles as described by Wilfong, (2009:166) thus:

We examined both traditional literature circle roles and new ones... and selected four: Discussion Director, Summarizer, Vocabulary Enricher, and Webmaster. Two of these roles are traditional roles: Discussion director and summarizer... vocabulary enricher is generally applied to non-fiction literature circles. The final one, webmaster was created ... to ask students to apply knowledge gained from reading to a variety of graphic organizers.

According to Wilfong (2009) the name textmasters was developed to reflect the nature of the strategy. This is based on the principle that for a student to be a "master" of any text he/she 
reads, he/she must be competent in all of the responsibilities he chooses such as ask good questions as directed by the discussion director, summarize what they read as initiated by the (summarizer), learn new words as given by the (vocabulary enricher), and organize important information into graphic organizers (webmasters). Each of these roles is given descriptions of what is expected of the student. For the discussion director, he/she develops a list of questions that his/her group might want to discuss about the part of the text being read, in this context, mathematics. His/her task is to help people in his/her group talk about the big ideas in the reading and share their directions. The summarizer on the other hand has a job of preparing a brief summary of each content area reading. Each group discussion starts with 1-2 minute/s statement that cover the key points, main highlights and general idea of the assignment. The vocabulary enricher looks out for a few important words that need clarification and marks them and later jot down their meanings either through contextual clues or by resorting to the dictionary or other sources available. The webmaster gathers all the information and makes a graphic organizers of such content to show degree of understanding. The webmaster can use keywords phrases and examples from the reading to make his/her organizers. Any type of graphic organizers could be used such as: Concept map, pyramid, K-W-L or even chat. Textmasters' environment requires the teacher to read aloud first in order to create a model and then the class is roused into a brainstorming section to enable the students get acquainted with the strategy.

\subsection{Purpose of the Study}

Based on the degree of fear often exhibited by most students towards mathematics as buttressed by the continuous failure purportedly reported by the Chief Examiners of the West African Examination Councils (WAEC) in Nigeria, there is a need to think of the possible ways of demystifying the dread of mathematics by consciously thinking of a feasible way out. Playing down on this fear could be done through poetry, which though is often regarded as abstract in nature, yet it is highly entertaining and has the potentials of capturing students' interest, if handled well. Thus, the main purpose of this study is to basically establish the feasibility of using poetry in a textmasters' environment for the sole purpose of fostering comprehension of mathematics. Therefore, this paper is not an empirical study, but instead an opinion paper that postulates on the feasibility of using poetry to teach mathematics via textmasters' environment.

\section{What Happens in a Textmasters' Environment?}

In a textmasters' meeting, the discussion director ignites the meeting by asking questions prepared on the role sheets by each of the participants. Discussion then follows each question. At the initial stage, the question and answer session is made as simple as ever, but as the students gains familiarity in the textmasters' environment, higher level questions are often asked and questions are often followed up by other questions. After that, the discussion director asks other members of the group to share roles and students often respond to each role with more questions and connections as appropriate. In conducting textmasters meeting a "fish bowl" sitting technique (Young 2007) is often adhered to. In this environment, a group of four students model the participation for the rest of the class before the whole class 
embarks on that. The chosen group usually sits in the centre of the classroom (in a fishbowl form) while the rest of the class circles them to watch. The moment the modus operand has been established, every member of the class gets assigned to a group of four and they all sit in a fish bowl manner so that the facilitator (the teacher) would always come into their midst as the need arises.

Textmasters' meeting is not a strategy that would be carried out every day because it takes time, rather the teacher will choose a time in the week when the class would have double periods in the timetable schedule for mathematics and execute it. It requires a period of 50 minutes as buttressed by Wilfong (2009). Every textmasters meeting day begins with a loud reading of about 5 minutes from the teacher through which he/she establishes a model and familiarity with the text. After that, the period begins fully with 20 minutes of silent reading of the assigned portion of the text and filling of the role sheets for the day, as designated by the role rotation. The next 20 minutes is for the sharing of ideas by each of the roles and for group work on the activities they would want to showcase at the end of the lesson. The final 10 minutes is set aside for self reflection.

During the time of silent reading, the teacher has the time to go round to the groups in their silent mood. The teacher stops intermittently to assist groups where necessary as he/she has the time to sit with any struggling students and often gives a one - to - one attention and assistance to such a student in need. Textmasters strategy gets students to really think and wonder.

\subsection{Reason for the Choice of Poetry in the Teaching of Mathematics via Textmasters' Environment}

Every student of literature would always have one or two things to say about poetry. Most teachers feel discomfort about teaching poetry. Many students have varied misconceptions about poetry ranging from its abstractness to some other negative attributes. Hughes and Dymoke (2009:48) reveal peoples' perceptions on "poetry" thus:

Students find poetry boring and resist it; poetry, as experienced by the teacher candidates in school was elitist and often in accessible; poetry exists on the periphery in most classrooms and it is considered to be a frill that is easily cut from English Programs when time constraints are involved; Poetry written by students is difficult to evaluate; an over emphasis on analysis is at the heart of most poetry teaching; and poetry is a solitary art.

From the above quotation, one can conclude that most students really have fear about poetry and try to avoid it, when they have the opportunity. I taught in a secondary school and had an ugly experience with my own students who never liked poetry. Their aversion for poetry started affecting my morale until I changed by approach and strategy for teaching poetry. When I did, I found out, to my utter amazement, that the mystery beclouding poetry was demystified by the song therapy I introduced. Subsequently, my students started liking poetry. Poetry is fun and the appreciation of poetry helps one to go beyond the literal scare to full 
enjoyment. A particular student teacher cited in Hughes and Dymoke (2009: 53) that:

It is clear that while the over analysis of poetry can be a distasteful experiences a close reading is still desirable and is in itself, pleasurable. It is important to approach it at various angles and keep it light and fun. Allow the students to explore the poetry rather than dissect it.

This quotation clarifies the mind bugging question on why I preferred that content area teachers should teach mathematics, of all the content areas, with a genre as difficult as poetry. The choice is basically because mathematics and poetry are fun depending on the approach that a teacher adopts in teaching it. Remember that a textmasters' environment affords the students in each of the groups the opportunity to learn from the more knowledgeable others in their group.

Literacy is important to mathematics learning (Draper, 2002), particularly to the National Council of Teachers of Mathematics (NCTM), which recommended in 2000 that students should do more reading, writing and discussing ideas in the mathematics classroom and learn mathematical ideas in real world context. Researches have found that literature is a powerful tool for integrating literacy and mathematics (Burns, 2004; Shatzer, 2008) and that reading, writing and even drawing are important in mathematics learning (Adams, 2003). According to Crespo and Kyriakides as cited in Bintz Moore, Wright \& Dempsey (2011: 59) "drawing can be a powerful way of engaging many students, especially young ones, in representing and communicating their mathematical ideas. It also helps students to support, solidify and extend mathematical ideas". When good literacy and mathematics are integrated, math scores increase because standards based math strategies are combined with high quality literature (Jennings 1992).

However, not all literature will work well in classrooms. It is important to note that the promotion of a literature text by both publishers and teachers as a good source to integrate literature and mathematics in the classrooms is not a guarantee that the piece is a good literature for teaching important mathematical concepts accurately, correctly and effectively. Schiro as cited in Bintz, Moore Wright and Dempsey (2011), asserts that it is only literature that is rigorously and systematically assessed for its quality and value for teaching mathematics will suffice. Hunsader (2004: 621) developed a good rubrics that could be used to assess the value of a variety of mathematics trade books and focused on the following:

- Is the book's mathematics content correct and accurate

- Is the book's mathematics content visible and effectively presented?

- Is the book's mathematics content intellectually and developmentally appropriate for the audience?

- Does the book facilitate the reader's enrolment in and use and transfer of its mathematics?

- Does the book's mathematics and story complement each other? 
- How great are the resources needed to help readers benefit from the book's mathematics?

Having established the rubrics needed from a good mathematical textbook, we shall now consider a mathematical poem that could be appreciated in a reading class through textmasters' strategy.

\section{Using Mathematical Poetry in a Textmasters Environment}

This paper exposes the types of content areas issues that could be rendered into a poem and share in a textmasters' environment as exemplified below in a composed poem on" simple interest". This is an example of what this paper aims at sharing with content area teachers. The poem centres on "simple interest" which is a financial term in mathematics. In trying to compose this poem, the writer deliberately decided to limit the appearance of figures and concentrated more on using a conversational poem so that the learners will ordinarily be carried along without the consciousness of the presence of the dreaded figures that liter the content area of mathematics. Savour the fun of playing down on figures with me thus:

\subsection{A Poem on Simple Interest}

\section{Simple Interest}

1 Mr. Jims likes to borrow money

He is a borrower, seeking for help

Who does he seek help from?

From a financial institution called a bank, which lends

But always expects a charge from the borrowers

\section{A charge?}

Yes, a charge called compensation

Compensation! For what?

Compensation as the interest for the loan

2 The money, Mr. Jims, borrowed is called principal

Is it a Principal of a school?

No, it is a financial term

This is to be paid back within a stipulated period

It may be in weeks, months, year or years.

That period is called a time

The amount of compensation for the loan is a rate

That is what we call simple interest

3 In simple interest, stipulated time determines period of payment

The interest is not added to the principal 
Why is it so?

Because the principal remains the same each year

Do you know that it has a formula?

No please teach me that!

$\mathrm{I}=\underline{\mathrm{P} \times \mathrm{T} \times \mathrm{R}}$

100

What are these letters for?

They mean the formula.

Formula?

Yes, for the Simple interest

4 This is the full meaning of those letters

Principal $\mathrm{x}$ Time $\mathrm{x}$ Rate

100

With this formula, my good student,

Simple interest problems could easily be solved by

Substituting the appropriate values with any of these formulae.

Have you learnt my lesson my dear child?

Yes! Yes!! and yes!!!

Thank you very much, sir

$5 \quad$ Now can you solve this problem for me?

Which one sir?

Find the simple interest on a loan of $\$ 2700$ for $6 \frac{1}{4}$ years at $3 \%$ per annum.

Quite simple! Wait and take the answer

Here is the answer!

$$
\begin{aligned}
& \mathrm{I}=\frac{\operatorname{PxT\times R}}{100} \\
& =\frac{2700 \times 6^{1 / 4} \times 3}{100} \\
& =\quad \$ 506.25 .
\end{aligned}
$$

Quite correct answer!

What a simple way for a simple interest!

(my composition)

From the example given in the above poem, mathematical and financial terms on simple interest have been so trivialized in these poetic stanzas such that any student who has phobia for figures would tend to play along with this conversational poem without being so conscious of figures littered therein, because they seem to have been demystified through the 
lyrics and rhythms of this poem - "simple interest". This poem was intentionally composed by me using a very familiar language and mild vocabulary to aid comprehension. It focused on using literature to teach mathematics thereby integrating both literacy and mathematics standards. This is important because they complement each other in powerful ways and also offers means for the development of mathematics and language skills simultaneously as learners listen, read, write and talk about mathematics (Hellwig, Moore and Jacobs, 2000).

\subsection{How would Students Discuss this Poem in a Textmasters'Environment/Classroom?}

There are certain steps that should be adhered to in trying to appreciate and discuss a poem in a textmasters' environment. These steps will act as guides to the implementation of textmasters' strategy. The underlisted steps are typical illustrations of such interaction:

Step I: Model reading by the Teacher. The teacher is expected to indicate a model read aloud first, which will teach the students how to read a poem. In the course of the reading, the teacher is expected to stress the mathematical words in the poem.

Step II: Having established a model reading, he/she should encourage the students to go into silent reading. During this period, each student in the group will begin to work on the role sheets by taking care of the responsibility given to him or her seriously. The teacher, who acts as a facilitator in this class, moves around looking for students, who are struggling with comprehension. She assists in fixing up the breakdown. Once the stipulated 20 minutes is over, the students move to the textmasters' task.

Step III: In a typical textmasters' environment, the students take responsibility of their learning in their fishbowl sitting style to brainstorm. In this instance, simple interest which has been relegated into a simple poem for obvious reasons. One of such reasons is that students enjoy hearing poetry read aloud to them by a competent model. The whole of this poem was based on "simple interest" and each person's role is to do justice to the topic based on the nature of each distinctive role given. These roles are described below:

The "discussion director" develops a list of questions that the group might want to discuss and he/she directs the flow of the discussion. Before he starts with questioning, he would also throw more light on the nature of the poem. After that, the "summarizer" takes the role of summarizing the poem read. The summarizer is expected to revisit the poem by paying great emphasis on the key points, main highlights and the general idea of the day's reading and assignment. He retells the story, rereads the poem from his own point of view and initiates the process of the appreciation of the poem. The "Vocabulary Enricher engages the group in some of the important words in the reading, which he may have jotted down in his role sheet during his private reading period. He tries to provide the meanings of the words contextually or by direct reference to the dictionary or any other sources available. The "Webmaster" has the most fantastic job. He takes the whole poem and renders it into any type of graphic organizers that he chooses to show understanding and the relationship that exist among the concepts that feature in the poems. The webmaster is at liberty to use any graphic organizer that he feels may be apt to enhance the maximum comprehension of the passage. 
Step IV: The students are now allowed to self evaluate themselves. It is time to evaluate their activities and equally come up with more activities and facts that will boost their presentation in any subsequent activity, which the class might embark on with respect to this lesson. The teacher might set aside a time, when each of the groups will present the submissions of their groups, so that he would review their degree of input and power of presentation. Roles are rotational. After each textmasters meeting, roles are reassigned to make sure that each student gets equal opportunity and responsibility as he / she takes different roles at different lessons.

\section{The Beauty of Using Textmasters Strategy in Learning}

Many benefits have been accrued to the use of textmasters' strategy. Some of which are briefly discussed below:

- Literature circle was applauded as a very beneficial instructional strategy that has fostered learning across the curriculum. Textmasters, being a modified version of literature circle is adjudged as an enhancing aid for easier comprehension. Wilfong (2009) believes that textmasters allows students to benefit a lot from the independent work time allotted to them which enables the teacher to have a one - to- one contact with students who are in dire need of attention.

- The textmasters enables each group to create variety of activities from a single poem read. Thereby diversifying interest and styles. They are helped into applying their new knowledge to these activities with a host of reading, writing and speaking skills (Wilfong 2009).

- Students learn a lot of vocabulary through their direct interaction with words in various capacities of the roles they are given.

- It also assists students into creative thinking because everybody has an assignment to produce something new and different from the others.

- It also encourages peer tutoring because every student has a role to work on and at the end, others learn from their findings.

- Textmasters strategy creates an enabling environment that assists the students into asking few questions during silent reading time as regards some unknown words.

- The heterogeneous arrangement in a textmasters environment inculcates the act of teaching through the rotation of roles embedded in it. Hear how (Wilfong 2009: 170): buttressed it thus:

The textmasters strategy brought students together not only to share their ideas about the textbook reading, but also to teach others through the culminating activity. As stated earlier, students benefit from listening to someone else's opinion about the reading and their excitement in asking and answering questions ... through the use of 
role sheets.

Textmasters provide motivation to reading because members of each group would not want to let their group down hence, the need for diligent study.

\section{Conclusion}

This paper has succeeded in discussing and illustrating ways through which we can bring in "rhythm of happiness" in the learning of mathematics through poetry in a textmasters' environment. It tried to showcase the fact that mathematics, even though it deals with scaring "figures and terminologies", yet it could also be successfully rendered into a fun activity in a typical poetry class via textmasters. It promotes the social constructivism theory, where learning takes place in a social learning situation and concludes on the note that mathematics and its peculiar figures remains an unfamiliar friend to many students, but can be successfully reduced into a most cherished/friendly subject of study, if the mathematical symbols are transformed into rhythm of happiness through poetry in a textmasters' environment. It is indeed a very powerful tool in dealing with interdisciplinary curriculum.

\section{References}

Bintz, W. P., Moore S. D., Wright, P., \& Dempsery, L. (2011). Using literature to teach measurement. The Reading Teacher, 55(1), 58-70.

Burns, M. (2004). 10 big maths ideas. Instruction Magazine, 113(7), 16-19. http://dx.doi.org/10.1598/RT.65.1.8

Danels, H. (1994). Literature circles: Voice and choice in the student centred classroom. York M. E: Stenhouse.

Draper, R. J. (2002). School mathematics reform, construction and literacy: A case for literacy instruction is the reform - oriented math classroom. Journal of Adolescent \& Adult Literacy, 45(6), 520-529.

Dymoke.., S., \& Hughes, J. (2009). Using a poetry Wiki: How can the medium support pre-service about teaching poetry writing in a digital age? English Teaching: Practice and Critique, 8(3), 91-106.

Hughes, J., \& Dymoke, S. (2011). Wiki-Ed poetry: Transforming preservice teachers' preconceptions about poetry and poetry teaching. Journal of Adolescents and Adult Literacy 55(1), 46-56. http://dx.doi.org/10.1598/JAAL.55.1.5

Hunsder, P. D. (2004). Mathematics trade books: Establishing their value and assessing their quality. The Reading Teacher, 57(7), 618-629.

Jennings, C. M. (1992). increasing interest and achievement in mathematics through children's literature. Early Childhood Research Quarterly, 7(2), 263-276. 


Mll Macrothink

http://dx.doi.org/10.1598/RT.61.8.6

Peterson, S., \& Belizaire, M. (2006). Another look at roles in literature circles. Middle School Journal, 37(4), 37413.

Sandmann, A., \& Gruhler, D. (2007). Reading is thinking: Connecting readers to text through literature circles. International Journal of Learning, 13 (10), 105-114.

Shatzer, J. (2008). Picture book power: connecting children's literature and mathematics. The Reading Teacher, 61(8), 649-653.

Wilfong, L. G. (2009). Textmasters: Bringing literature circles to textbook reading across the curriculum. Journal of Adolescent \& Adult Literacy 53(2),164-171.

\section{Copyright Disclaimer}

Copyright for this article is retained by the author(s), with first publication rights granted to the journal.

This is an open-access article distributed under the terms and conditions of the Creative Commons Attribution license (http://creativecommons.org/licenses/by/3.0/). 